\title{
Phenotypic, fermentation characterization, and resistance mechanism analysis of bacteriophage-resistant mutants of Lactobacillus delbrueckii ssp. bulgaricus isolated from traditional Chinese dairy products
}

\author{
Kaibo Deng, ${ }^{*} † \ddagger$ Wei Fang, $\S$ Baodong Zheng, ${ }^{*}$ Song Miao, $\$ \ddagger^{1}$ and Guicheng Huo $\S^{1}$ \\ ${ }^{*}$ College of Food Science, Fujian Agriculture and Forestry University, Fuzhou, China 350002 \\ †China-Ireland International Cooperation Center for Food Material Science and Structure Design, Fujian Agriculture and Forestry University, \\ Fuzhou, China 350002 \\ †Teagasc Food Research Centre, Moorepark, Fermoy, Co. Cork, Ireland P61R966 \\ §Key Laboratory of Dairy Science, Ministry of Education, Northeast Agricultural University, Harbin, China 1500030
}

\section{ABSTRACT}

Bacteriophage infection is a large factor in dairy industrial production failure on the basis of pure inoculation fermentation, and developing good commercial starter cultures from wild dairy products and improving the environmental vigor of starter cultures by enhancing their phage resistance are still the most effective solutions. Here we used a spontaneous isolation method to obtain bacteriophage-resistant mutants of Lactobacillus delbrueckii ssp. bulgaricus strains that are used in traditional Chinese fermented dairy products. We analyzed their phenotypes, fermentation characteristics, and resistance mechanisms. The results showed that bacteriophage-insensitive mutants (BIM) BIM8 and BIM12 had high bacteriophage resistance while exhibiting fermentation and coagulation attributes that were as satisfying as those of their respective parent strains KLDS1.1016 and KLDS1.1028. According to the attachment receptor detection, mutants BIM8 and BIM12 exhibited reduced absorption to bacteriophage phiLdb compared with their respective bacteriophage-sensitive parent strains because of changes to the polysaccharides or teichoic acids connected to their peptidoglycan layer. Additionally, genes, including HSDR, HSDM, and $H S D S$, encoding 3 subunits of a type I restrictionmodification system were identified in their respective parent strains. We also discovered that $H S D R$ and $H S D M$ were highly conserved but that $H S D S$ was variable because it is responsible for the DNA specificity of the complex. The late lysis that occurred only in strain KLDS1.1016 and not in strain KLDS1.1028 suggests that the former and its mutant BIM8 also may have an activatable restriction-modification mechanism. We conclude that the L. bulgaricus BIM8 and BIM12

\footnotetext{
Received September 12, 2017

Accepted November 3, 2017.

${ }^{1}$ Corresponding authors: song.miao@teagasc.ie and gchuo58@126.
} com mutants have great potential in the dairy industry as starter cultures, and their phage-resistance mechanism was effective mainly due to the adsorption interference and restriction-modification system.

Key words: Lactobacillus delbrueckii ssp. bulgaricus, spontaneous mutation, starter culture, bacteriophageresistant mechanism

\section{INTRODUCTION}

Lactobacilli are probiotic organisms used in the production and preservation of fermented foods of plant and animal origin (Parvez et al., 2006). Abundant lactobacilli strain resources are found in many traditional fermented dairy products, and Lactobacilli delbrueckii ssp. bulgaricus (L. bulgaricus) starter cultures available today for yogurt production are derived from artisanal starters with satisfactory technological (flavor and textural) properties and health benefits (Parente and Cogan, 2004; Carminati et al., 2010). One of the most significant and persistent problems in yogurt processes is the contamination of the starters by bacteriophages that cause fermentation failure or retardation as well as great economic losses (Emond and Moineau, 2007).

The phage contamination sources could be raw milk, processed or recycled ingredients, air and surfaces, and lactic acid bacteria themselves (Garneau and Moineau, 2011). Phage control strategies have been reported to be based on phage proliferation control, strain selection and starter rotation systems, bacteriophage-insensitive bacterial mutants, phage-resistant starter design, and anti-phage systems (González et al., 2010; Labrie et al., 2010). Even if some disadvantages have been encountered when using natural processes based on spontaneous mutation and adaptation (Garcia-Doval and van Raaij, 2013), they have been proven to be a better approach than manmade transformation because they are more convenient, simple, and natural and are not subject to any regulatory restrictions (Moineau and 
Lévesque, 2004). Additionally, phage-resistant mutants have been shown to successfully retain their original probiotic and technological attributes (Briggiler Marcó et al., 2014; Capra et al., 2014; Zago et al., 2017). These phage-resistant cultures were created traditionally by recombinant DNA technology (McGrath et al., 2002) or plasmid transformation with resistant genes (Pillidge et al., 2000). Although some problems are still associated with such mutants, secondary infection has been affirmed recently because it is a simple and natural methodology that does not involve any genetic manipulation (Guglielmotti et al., 2006).

In previous studies, we identified a series of wild $L$. bulgaricus strains preserved by the Dairy Industrial Culture Collection, Key Lab of Dairy Science, Ministry of Education, China. These strains were obtained from Chinese traditional fermented dairy products, and they exhibited excellent flavor, viscosity, postacidification production characteristics, and key enzyme expression features (Liu et al., 2013; Hou et al., 2015; Li et al., 2017). However, their bacteriophage-resistance capacities have not been studied before. Bacteriophage resistance is an indispensable characteristic of commercial starter cultures, so improving their bacteriophage resistance is of great importance. Thus, the aim of the present work was to spontaneously induce the bacteriophage resistance of wild $L$. bulgaricus strains with good fermentation attributes and to investigate the phenotypes, fermentation attributes, and resistance mechanisms of the phage-resistant mutants.

\section{MATERIALS AND METHODS}

\section{Strains, Bacteriophage, and Culture Conditions}

The 8 strains of $L$. bulgaricus and bacteriophage phiLdb used in this study are listed in Table 1. Bac- teriophage phiLdb (accession no. NC022762.1), which was isolated from Chinese yogurt and kindly provided by Jian Kong, is a virulent phage of $L$. bulgaricus ATCC $11842^{\mathrm{T}}$ (Wang et al., 2010). All these facultative anaerobic strains were grown in De Man, Rogosa and Sharpe (MRS) broth at $37^{\circ} \mathrm{C}$, and the bacterial suspensions were stored at $-80^{\circ} \mathrm{C}$ in $30 \%$ (vol/vol) glycerin. Bacteriophage phiLdb was cultured overnight with the host strain sludge of L. bulgaricus ATCC $11842^{\mathrm{T}}$ (multiplicity of infection, MOI $=0.5$ ) in MRS-Ca broth (MRS with $\mathrm{CaCl}_{2}$ to a final concentration of $10 \mathrm{mM}$ ) at $37^{\circ} \mathrm{C}$ until total lysis was observed (Wang et al., 2010). The lysates were obtained by centrifugation $(8,000 \times g$, $10 \mathrm{~min}$ ) and passed through a $0.22-\mu \mathrm{m}$ filter, and then phage particles were concentrated with $0.5 \mathrm{~mol} / \mathrm{L}$ of $\mathrm{NaCl}$ and $10 \%$ (wt/vol) polyethylene glycol 8000 on ice for $1 \mathrm{~h}$, followed by centrifugation $(12,000 \times g, 20 \mathrm{~min})$ and resuspension in suspension medium buffer $[0.58 \%$ $\mathrm{NaCl}, 0.2 \%$ (wt/vol) $\mathrm{MgSO}_{4} \cdot 7 \mathrm{H}_{2} \mathrm{O}$, and $1 \mathrm{~mol} / \mathrm{L}$ Tris$\mathrm{HCl}(\mathrm{pH} 7.5)]$.

\section{Selection of the Bacteriophage Host Strains}

Cultures containing $0.1 \mathrm{~mL}$ of the phiLdb resuspension and $0.1 \mathrm{~mL}$ of the overnight cultured L. bulgaricus strains were added to $3 \mathrm{~mL}$ of MRS broth containing $0.7 \%$ (wt/vol) agar at a constant temperature of $47^{\circ} \mathrm{C}$ and mixed well. After a 15-min adaptation, the mixture was cultured as the upper layer medium above an MRS-Ca plate containing 1.8\% (wt/vol) agar for $24 \mathrm{~h}$ at $37^{\circ} \mathrm{C}$. Strains that yielded plaques were considered to be host strains of bacteriophage phiLdb.

\section{Isolation of Spontaneous Phage-Resistant Mutants}

The sensitive strains were inoculated $(2 \% \mathrm{vol} / \mathrm{vol})$ in MRS-Ca broth with bacteriophage phiLdb at an

Table 1. Bacterial strains and bacteriophage used in this study

\begin{tabular}{|c|c|}
\hline Item & Source $^{1}$ \\
\hline \multicolumn{2}{|l|}{ Strain $^{2}$} \\
\hline L. bulgaricus KLDS1.1027 & KLDS-DICC; isolated from Qinghai traditional fermented dairy, China \\
\hline L. bulgaricus KLDS1.1028 & KLDS-DICC; isolated from Qinghai traditional fermented dairy, China \\
\hline L. bulgaricus KLDS1.1012 & KLDS-DICC; isolated from Qinghai traditional fermented dairy, China \\
\hline L. bulgaricus KLDS1.1013 & KLDS-DICC; isolated from Qinghai traditional fermented dairy, China \\
\hline L. bulgaricus KLDS1.0501 & KLDS-DICC; isolated from Xinjiang traditional fermented dairy, China \\
\hline L. bulgaricus KLDS1.1009 & KLDS-DICC; isolated from Heilongjiang traditional fermented dairy, China \\
\hline L. bulgaricus KLDS1.1016 & KLDS-DICC; isolated from Inner Mongolia traditional fermented dairy, China \\
\hline L. bulgaricus KLDS1.1006 & KLDS-DICC; isolated from Inner Mongolia traditional fermented dairy, China \\
\hline L. bulgaricus ATCC $11842^{\mathrm{T}}$ & ATCC \\
\hline \multicolumn{2}{|l|}{ Bacteriophage } \\
\hline phiLdb & Isolated from Chinese yogurt (Wang et al., 2010) \\
\hline
\end{tabular}

${ }^{1}$ KLDS-DICC $=$ Key Laboratory of Dairy Science, Ministry of Education-Dairy Industrial Culture Collection, China. ATCC = American Type Culture Collection.

${ }^{2}$ L. bulgaricus $=$ Lactobacillus delbrueckii ssp. bulgaricus. 
MOI of 1.0, and they were cultivated for $36 \mathrm{~h}$ at $37^{\circ} \mathrm{C}$. Then, they were diluted to the proper concentration, followed by cultivation on MRS agar medium using the spread plate count method. After incubation for $48 \mathrm{~h}$ at $37^{\circ} \mathrm{C}$, isolated colonies on each host strain phage plate were picked, purified by 3 consecutive rounds of streaking on MRS agar, and cultured in MRS broth for enrichment. To confirm the phage resistance and to remove false positives, the putative mutants were subcultured 3 times in MRS-Ca broth with higher doses of bacteriophage phiLdb, and the batches that showed the same absorbance (at $600 \mathrm{~nm}$ ) as those growing in MRS-Ca broth without phage were regarded as true phage-resistant mutants (Guglielmotti et al., 2006). Efficiency of plating (EOP) was determined as the index of the bacteriophage-resistance capacity of the positive mutants, which was indicated by the ratio of phage plaques in resistant mutants to sensitive strains and was determined according to Kutter (2009).

\section{Randomly Amplified Polymorphic DNA-PCR Analysis}

Genomic DNA of the parent strains and the bacteriophage-resistant mutants was obtained using the TIANamp Bacteria DNA kit (Tiangen, Beijing, China) and quantified by electrophoresis in $0.8 \%$ (wt/vol) agarose gels (regular, Biowest, Nuaillé, France). Randomly amplified polymorphic DNA (RAPD) PCR was conducted to determine their genetic similarity to eliminate false-positive and contaminating strains. Four oligonucleotide primers (1254, 1281, D8635, and D14216) were used in separate amplification assays (Akopyanz et al., 1992). The PCR amplification was performed in a volume of $25 \mu \mathrm{L}$ containing $2.5 \mu \mathrm{L}$ of $10 \times$ PCR buffer, $200 \mu M$ each dNTP, $1.5 \mathrm{~m} M \mathrm{MgCl}_{2}, 1.25 \mathrm{U}$ of Taq DNA polymerase (Sangon Biotech, Shanghai, China), $2.0 \mu \mathrm{L}$ of template DNA, and $0.6 \mu M$ each primer for each assay. A thermocycler (Bio-Rad, Hercules, CA) was used, and the PCR program for primers 1254 and 1281 was as follows: 4 cycles of amplification $\left(94^{\circ} \mathrm{C}\right.$ for $5 \mathrm{~min}, 36^{\circ} \mathrm{C}$ for $5 \mathrm{~min}$, and $72^{\circ} \mathrm{C}$ for $5 \mathrm{~min}$ ), followed by 30 cycles of amplification $\left(94^{\circ} \mathrm{C}\right.$ for $1 \mathrm{~min}, 36^{\circ} \mathrm{C}$ for 1 min, and $72^{\circ} \mathrm{C}$ for $2 \mathrm{~min}$ ), followed by a final extension $\left(72^{\circ} \mathrm{C}\right.$ for $\left.10 \mathrm{~min}\right)$. For primers D8635 and D14216, the PCR program was as follows: 4 cycles of amplification $\left(94^{\circ} \mathrm{C}\right.$ for $1 \mathrm{~min}, 36^{\circ} \mathrm{C}$ for $1 \mathrm{~min}$, and $72^{\circ} \mathrm{C}$ for $\left.2 \mathrm{~min}\right)$, followed by 30 cycles of amplification $\left(94^{\circ} \mathrm{C}\right.$ for $1 \mathrm{~min}$, $55^{\circ} \mathrm{C}$ for $1 \mathrm{~min}$, and $72^{\circ} \mathrm{C}$ for $2 \mathrm{~min}$ ), followed by one 10 -min extension at $72^{\circ} \mathrm{C}$. Amplification products were detected by electrophoresis in 1\% (wt/vol) agarose gels (regular, Biowest) containing $200 \mu \mathrm{g} / \mathrm{mL}$ of ethidium bromide (Sigma-Aldrich, St. Louis, MO) and viewed by UV transillumination at $254 \mathrm{~nm}$.

\section{Characterization of Phage-Resistant Mutants}

To determine whether the growth of the phageresistant mutants was sustainable, the mutants were inoculated $(2 \% \mathrm{vol} / \mathrm{vol})$ in 2 sets of tubes containing MRS-Ca broth and were cultivated at $37^{\circ} \mathrm{C}$ for $10 \mathrm{con}$ secutive subcultures. Bacteriophage phiLdb was added to one set of the tubes, whereas the other set of tubes served as the control group. The absorbance of the bacterial suspensions in each set of tubes was detected at $600 \mathrm{~nm}$.

The lysogens in the phage-resistant strains were also examined. The positive mutants were cultured overnight in MRS-Ca broth at $37^{\circ} \mathrm{C}$ and concentrated by centrifugation $(8,000 \times g$ for $10 \mathrm{~min})$, and the suspension was analyzed by double-layer plaque titration to determine the growth state of the bacteriophage plaques (Marcó et al., 2011).

To detect the dairy fermentation capability of the bacteriophage-resistant mutants compared with the parent strains, they were inoculated $(2 \% \mathrm{vol} / \mathrm{vol})$ in skim milk medium $(12 \% \mathrm{wt} / \mathrm{vol})$ containing $1.0 \times 10^{8}$ plaque-forming units $/ \mathrm{mL}$ of bacteriophage phiLdb and cultured at $42^{\circ} \mathrm{C}$. The fermentation of the mutants in skim milk without bacteriophage phiLdb served as a control. The best strains in terms of coagulation time and $\mathrm{pH}$ were screened for further cultivation $(2 \%$ $\left.\mathrm{vol} / \mathrm{vol} ; 42^{\circ} \mathrm{C}\right)$ in skim milk $(12 \% \mathrm{wt} / \mathrm{vol})$. Then, the fermentation characteristics of the best mutants were assessed, including viable bacteria counts, $\mathrm{pH}$ (Delta $320 \mathrm{pH}$ meter; Mettler Toledo, Columbus, OH) at 12 $\mathrm{h}$, and a texture profile analysis for viscosity (TA.XT Plus texture analyzer; Stable Micro Systems, Surrey, $\mathrm{UK})$ at $6 \mathrm{~h}$. The parameters for viscosity detection were as follows: probe type $=\mathrm{p} / 0.5$; falling speed $=$ $2.0 \mathrm{~mm} / \mathrm{s}$; test speed $=1.0 \mathrm{~mm} / \mathrm{s}$; return speed $=2.0$ $\mathrm{mm} / \mathrm{s}$; press deformation $=10 \mathrm{~mm}$; and trigger force $=0.04 \mathrm{~N}$.

\section{Phage Adsorption}

Cell wall extraction was performed as described previously (Quiberoni et al., 2000) with the modification to MRS broth for the bacterial cultivation. The adsorption percentages were determined as follows: overnight cultures of the sensitive and resistant strains were inoculated ( $2 \% \mathrm{vol} / \mathrm{vol})$ in MRS-Ca broth (optical density $=0.3$ at $600 \mathrm{~nm}$ ) at $37^{\circ} \mathrm{C}$, and then the cultures were infected with bacteriophage phiLdb at the optimal MOI of each mutant. After cultivation (30 min, $37^{\circ} \mathrm{C}$ ), the supernatant was obtained by centrifugation $(8,000 \times g, 10 \mathrm{~min})$, and the bacteriophage titers were determined (Quiberoni et al., 2003). We used MRS-Ca broth without the strains as a control. The degree of 
phage adsorption was expressed as the percentage of the obtained cell titers.

\section{Identification of the Cellular Attachment Receptor for Phage phiLdb}

The optimal phage-binding concentration was examined, and it was defined as the cell wall concentration that was bound by $90 \%$ of the bacteriophages and calculated by a previously published method (Valyasevi et al., 1990). Cell walls of the bacteriophage-resistant mutants were treated with $0.1 \mathrm{mg} / \mathrm{mL}$ of proteinase $\mathrm{K}, 50 \mathrm{U} / \mathrm{mL}$ of lysozyme, $1 \%$ (vol/vol) SDS, and $5 \%$ (vol/vol) trichloroacetic acid (TCA), and they were added to a $50 \mathrm{~m} M$ Tris-hydrochloride solution of bacteriophage phiLdb $\left(10^{8}\right.$ plaque-forming units $/ \mathrm{mL}, \mathrm{pH}$ 6.8 ) at the optimal phage-binding concentration level. After incubation under certain conditions $\left(37^{\circ} \mathrm{C}\right.$ for 30 min for the proteinase $\mathrm{K}$, lysozyme, and SDS treatments and $100^{\circ} \mathrm{C}$ for $15 \mathrm{~min}$ for the TCA treatment), all the samples were washed $(10 \mathrm{mmol} / \mathrm{L}$ of PBS, $\mathrm{pH}$ $6.8)$ and centrifuged $(12,000 \times g, 15 \mathrm{~min})$ immediately, and the phage adsorption percentages were determined as above. Untreated cell wall samples were used as a control.

\section{Restriction-Modification System Detection}

Restriction-modification $(\mathbf{R} / \mathbf{M})$ systems may exist in phage-resistant mutants that exhibit high adsorption percentages to bacteriophages and late lysis in broth. The $\mathrm{R} / \mathrm{M}$ resistance mechanism was investigated according to Clara et al. (1990) and Binetti et al. (2007b) with the following modifications. In stage 1, bacteriophage phiLdb was cultivated in an L. bulgaricus KLDS1.1028 culture, and the first EOP value (EOP1) was determined (Kutter, 2009). In stage 2, one lysis plaque (named phiLdb-a) obtained from the titration was picked up, suspended in $5 \mathrm{~mL}$ of MRS-Ca broth, and stored at $4^{\circ} \mathrm{C}$ for $16 \mathrm{~h}$. The phiLdb-a suspension was inoculated in $2 \mathrm{~mL}$ of an L. bulgaricus KLDS1.1016 overnight culture and cultivated at $37^{\circ} \mathrm{C}$ until total lysis was observed. The lysate was filtered through a $0.22-$ $\mu \mathrm{m}$ membrane and titrated to determine the second EOP value (EOP2). In stage 3, from the L. bulgaricus KLDS1.1016 plate, one lysis plaque (named phiLdb-b) was also picked up and the same approach as above was used. The phiLdb-b suspension was inoculated in 2 $\mathrm{mL}$ of an L. bulgaricus KLDS1.1028 overnight culture and cultivated at $37^{\circ} \mathrm{C}$ until total lysis was observed. The obtained lysate was filtered through a $0.22-\mu \mathrm{m}$ membrane, and the third EOP value (EOP3) was determined.

\section{Amplification of Genes Encoding R/M Systems}

There are 3 main types of $\mathrm{R} / \mathrm{M}$ systems (types $\mathrm{I}$, II, and III), which are determined according to the conserved sequences in the encoding genes (Forde and Fitzgerald, 1999). This approach has been effective for identifying the presence of $\mathrm{R} / \mathrm{M}$ systems through PCR sequence amplification and alignments with related genes in identified standard strains (Capra et al., 2011). Primers designed to amplify the conserved features of genes encoding $\mathrm{R} / \mathrm{M}$ systems of the bacteriophageresistant mutants are shown in Table 2, and PCR amplification, DNA recovery, and plasmid extraction kits and plasmids and competent cells were purchased from Takara (Dalian, Shandong, China). Pairwise similarity alignments were performed between the amplified sequences and the HSDS, HSDR, and HSDM sequences of R/M systems from GenBank at the National Center for Biotechnology Information (Bethesda, MD) using DNAman 6.0 (Lynnon Biosoft, San Ramon, CA).

\section{Data Analysis}

A GelDoc-It Imaging System equipped with GelCam 315 (UVP, Upland, CA) and Quantity One software was used to obtain and analyze photographs of agarose gels under UV illumination. Similarities of the PCR fingerprinting profiles were calculated based on Pearson correlation coefficient. The application of the unweighted pair group method with arithmetic averages allowed a dendrogram to be built from the matrix of similarities (Vauterin and Vauterin, 1992). All assays were examined in triplicate, and the results were expressed as means \pm standard deviations. Statistical data analysis was performed using Excel 2010 software (Microsoft Corp., Redmond, WA).

\section{RESULTS}

\section{Isolation of Bacteriophage-Resistant Mutants from Host Strains}

Eight strains of L. bulgaricus (Table 1) were used to identify the host strains of bacteriophage phiLdb, and the results showed that L. bulgaricus strains KLDS1.1016 and KLDS1.0128 displayed apparent plaques on double-layer culture plates, which signified that they were host strains of bacteriophage phiLdb. Thus, these strains were primarily studied in the following research.

The host strains of bacteriophage phiLdb, L. bulgaricus KLDS1.1016 and KLDS1.0128, were mutated spontaneously to obtain bacteriophage-insensitive mutants 
(BIM). After cultivation and purification, 10 single colonies (named BIM1 to BIM10) were isolated from L. bulgaricus strain KLDS1.1016, and 7 single colonies (named BIM11 to BIM17) were isolated from L. bulgaricus strain KLDS1.0128. The EOP of all 17 mutants was determined, and the results showed that there were no plaques on the plates, which implied that the mutants were totally phage resistant $\left(\mathrm{EOP}<1.8 \times 10^{-8}\right)$.

\section{RAPD-PCR}

Four primers (1254, 1281, D8635, and D14216) were used for RAPD-PCR as described previously (Akopyanz et al., 1992; Torriani et al., 1999; Gu et al., 2012). In this study, the bands from $L$. bulgaricus strains KLDS1.1016 and KLDS1.1028 were shown to exhibit a high concordance between the sensitive parents and the corresponding resistant mutants. The dendrogram of the parent strains and the resistant isolates also showed that the coefficient of genetic similarity reached as high as $80 \%$ using Quantity One software (version 4.6.2; BioRad; Figures 1 and 2). Furthermore, the band length of mutants was not found to be changed compared with the respective parent strains, which indicates that the mutants' genomes do not have any base insertions or deletions. However, we cannot rule out the possibility of nucleotide variances such as base substitution, which may not result in DNA mismatch during RAPD-PCR amplification.

\section{Resistance Stability of the Bacteriophage- Resistant Mutants}

All the bacteriophage-resistant mutants of L. bulgaricus strains KLDS1.1016 and KLDS1.1028 were cultured with bacteriophage phiLdb $(\mathrm{MOI}=1)$ at $37^{\circ} \mathrm{C}$ for 7 consecutive subcultures, and their growth rates did not differ significantly $(P<0.05)$ from those of their parent strains regardless of whether they were grown separately or together with bacteriophage phiLdb. The mutants were also shown to be nonlysogenic bacteria (data not shown). This may indicate that the resistant strains stably inherited their growth and phage resistance characteristics. During the lysogen detection of the 17 resistant mutants of the 2 parent strains, no plaques were found on the double-layer plates, which implied that all the resistant strains were nonlysogenic bacteria.

\section{Fermentation Characterization of the Phage- Resistant Mutants}

The coagulation features of the sensitive parent strains and the respective phage-resistant mutants were analyzed, and the results showed that coagulation did not appear during the first $12 \mathrm{~h}$ in the mixture of the sensitive hosts with bacteriophage phiLdb (Table 3), probably because the hosts could not proliferate as a result of the phage infection. However, milk curdling occurred in all the phage-resistant mutant cultures,

Table 2. Primers, plasmids, and competent cells used in this study

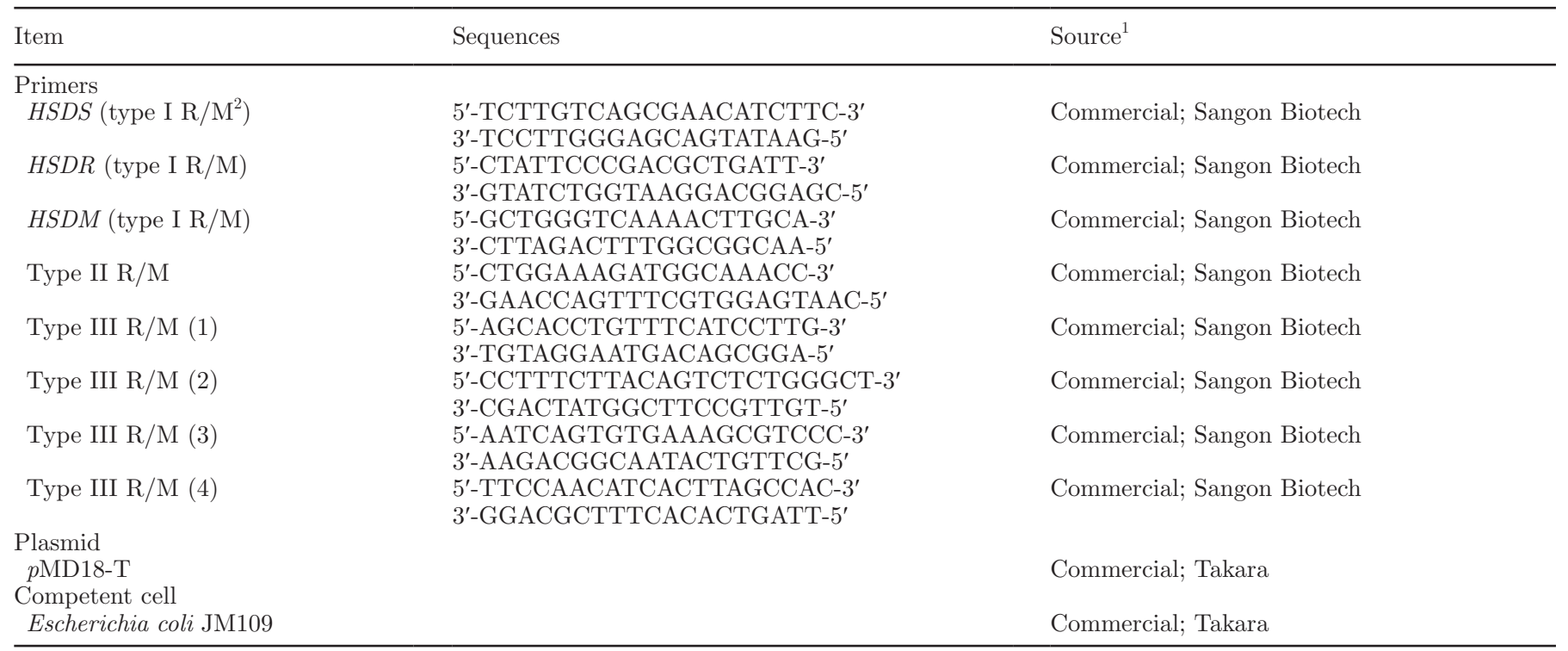

${ }^{1}$ Sangon Biotech, Shanghai, China. Takara, Dalian, Shandong, China.

${ }^{2} \mathrm{R} / \mathrm{M}=$ restriction and modification system. 


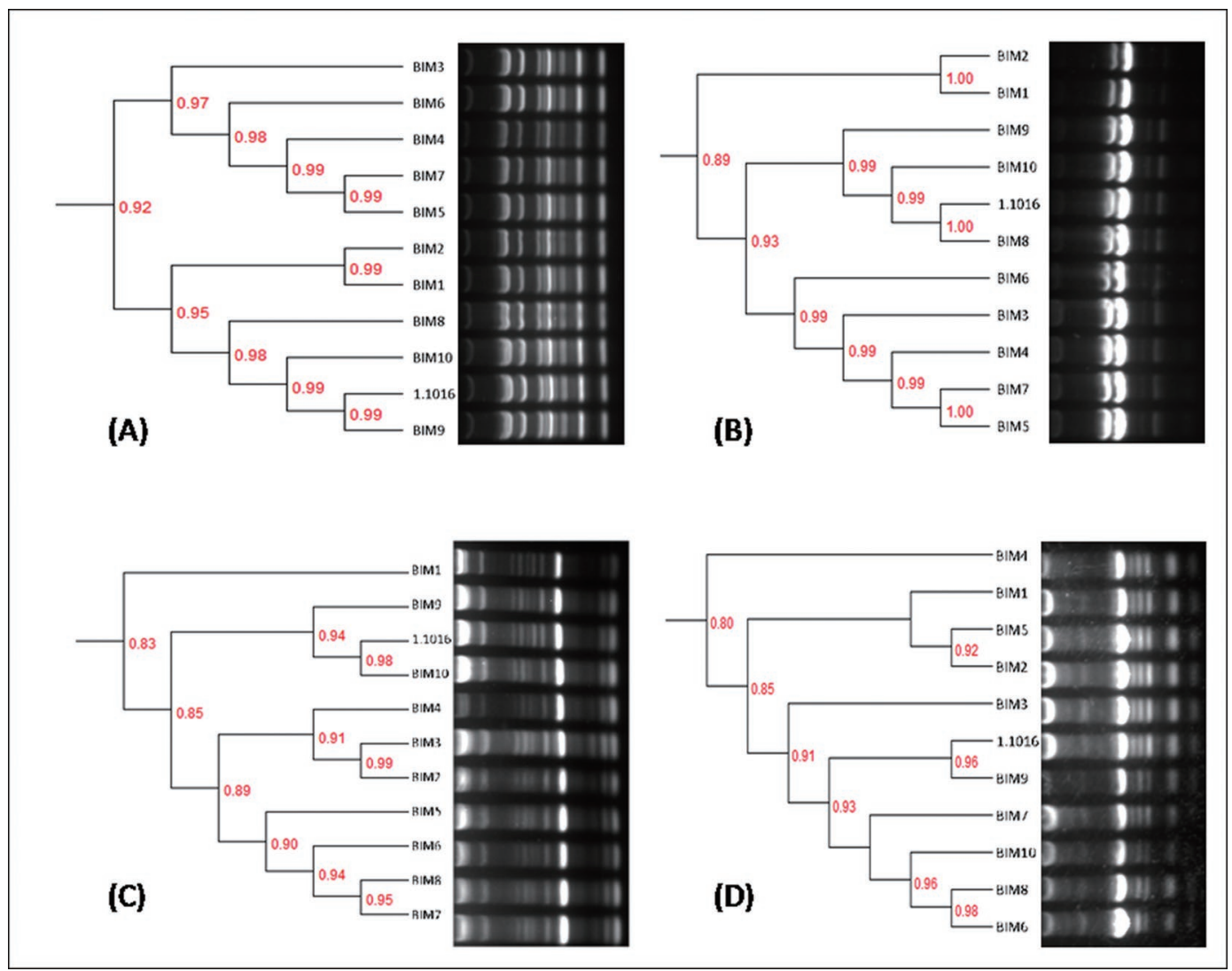

Figure 1. Randomly amplified polymorphic DNA PCR electrophoretogram and dendrogram of Lactobacillus delbrueckii ssp. bulgaricus strain KLDS1.1016 and its bacteriophage-insensitive mutants (BIM) BIM1 to BIM10. Genome sequences were replicated with primers of (A) 1254, (B) 1281, (C) D8635, and (D) D12416. The numbers on the phylogenetic trees indicate the genomic similarity using Quantity One 4.6.2 (Bio-Rad, Hercules, CA). Color version available online.

but the coagulation time of most of the mutants was significantly $(P<0.05)$ or extremely significantly $(P$ $<0.01$ ) higher than that of the parent strains, and the coagulation time varied considerably between different mutants. Meanwhile, the $\mathrm{pH}$ was also slightly higher when curdling occurred. Superficially, this signifies that the spontaneous mutants could reduce the milk clotting efficiency at different levels. Among the 17 phage-resistant mutants obtained from the 2 parent strains, only the coagulation properties of BIM8 and BIM12 did not differ significantly $(P>0.05)$ from those of their respective parent strains (Table 3); thus, they were used to conduct fermentation characteristic measurements to determine their potential feasibility as starter cultures compared with the original parent strains.

The growth and acidity characteristics in 2 treatments (culturing in broth with and without bacteriophage phiLdb) were examined in $L$. bulgaricus strains KLDS1.1016 and KLDS1.1028 and their respective resistant mutants BIM8 and BIM12. The viable bacteria counts and $\mathrm{pH}$ of the sensitive strains incubated with bacteriophage phiLdb exhibited extremely significant differences $(P<0.01)$ after $3 \mathrm{~h}$ of cultivation, and they remained relatively stable in both strains at a low level during the period of 3 to $12 \mathrm{~h}$ of incubation (Figure $3 \mathrm{~A}$ and $\mathrm{B}$ ). The $\mathrm{pH}$ values in the 2 treatments showed fundamentally the same variation as the viable bacterial counts at $6 \mathrm{~h}$, as the $\mathrm{pH}$ of the sensitive strains incubated with bacteriophage phiLdb was 5.8, whereas the $\mathrm{pH}$ of the sensitive strains incubated without bacteriophage phiLdb reached $4.7(P<0.01)$.

The mutants BIM8 and BIM12 also exhibited similar viscosity-producing characteristics, even in the presence of phages, compared with L. bulgaricus KLDS1.1016 and KLDS1.1028, respectively (Figure 4). The curd viscosity of the 3 treatments (sensitive strains incubated without phage and their respective mutants incubated with and without phage) did not exhibit any significant difference $(P>0.05)$, but it was significantly higher $(P$ $<0.01)$ than when the sensitive strains were incubated with phage. 


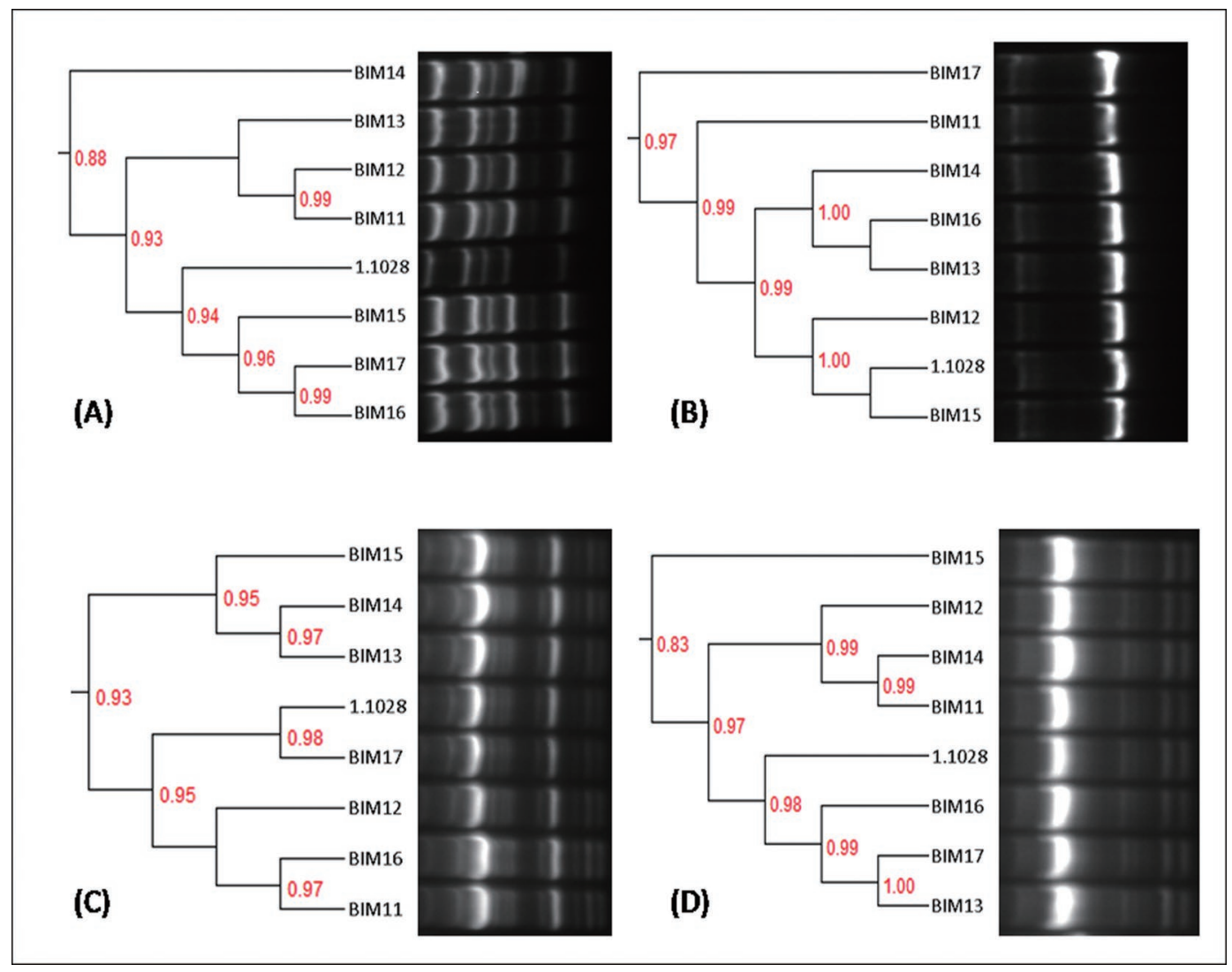

Figure 2. Randomly amplified polymorphic DNA PCR electrophoretogram and dendrogram of Lactobacillus delbrueckii ssp. bulgaricus strain KLDS1.1028 and its bacteriophage-insensitive mutants (BIM) BIM11 to BIM17. Genome sequences were replicated with primers of (A) 1254, (B) 1281, (C) D8635, and (D) D12416. The numbers on the phylogenetic trees indicate the genomic similarity using Quantity One 4.6.2 (BioRad, Hercules, CA). Color version available online.

\section{Identification of Cellular Attachment Receptors for Bacteriophage phiLdb}

The adsorption percentages of bacteriophage phiLdb to cells of the bacteriophage-resistant mutants ranged from 32 to $64 \%$, which were much lower than those of the sensitive parent strains, L. bulgaricus KLDS1.1016 and KLDS1.1028, whose absorption percentages were 98 and $97 \%$, respectively $(P<0.01$; Figure 5$)$. This implies that the cellular attachment receptors of the resistant strains may have undergone some functional modifications.

To prove this, cell walls isolated from the sensitive strains and the resistant mutants were treated with proteinase K, lysozyme, SDS, and TCA. The results showed that in the 4 tested L. bulgaricus strains, the lysozyme and TCA treatments resulted in significant decreases $(P<0.05)$ in the phage adsorption percentages compared with the control group, but no significant decreases $(P>0.05)$ were observed in the phage adsorption percentages for the proteinase $\mathrm{K}$ and
SDS treatments in either the sensitive parents or the resistant mutants (Table 4). Proteinase $\mathrm{K}$ is used for peptide hydrolysis (Wilson, 1987), and lysozyme is used for peptidoglycan hydrolysis (Nakimbugwe et al., 2006). Sodium dodecyl sulfate is used for membrane protein dissolution (Markwell et al., 1978), whereas TCA is used to remove polymers (e.g., polysaccharides and teichoic acids) linked with the peptidoglycan of the cell wall via acidolysis (Isaacson et al., 2006). This indicates that the cellular attachment receptors of $L$. bulgaricus KLDS1.1016 and KLDS1.1028 for bacteriophage phiLdb may be related to cell wall polymers in the peptidoglycan layer rather than membrane proteins.

\section{R/M System Detection}

The high cellular absorption percentage (Figure 5) and mass lysis from the second generation were observed in L. bulgaricus KLDS1.1016, which indicated that there is likely an $\mathrm{R} / \mathrm{M}$ mechanism in this strain (Binetti et al., 2007b). This inference can also be proven from the 
Table 3. Coagulation time and $\mathrm{pH}$ value of Lactobacillus delbrueckii ssp. bulgaricus strains KLDS1.1016 and KLDS1.1028 and their respective phage-resistant mutants BIM1 to BIM17

\begin{tabular}{lccc}
\hline Strain & $\begin{array}{c}\text { Phage } \\
\text { addition }\end{array}$ & $\begin{array}{c}\text { Coagulation time } \\
\text { (min unless noted })\end{array}$ & $\begin{array}{c}\text { Average } \\
\mathrm{pH}\end{array}$ \\
\hline KLDS1.1016 & - & $366 \pm 7.00$ & 4.68 \\
KLDS1.1016 & + & $>12 \mathrm{~h}$ & - \\
BIM1 & + & $436 \pm 10.21^{*}$ & 4.76 \\
BIM2 & + & $439 \pm 15.39^{*}$ & 4.91 \\
BIM3 & + & $493 \pm 6.56^{*}$ & 4.79 \\
BIM4 & + & $388 \pm 8.00^{*}$ & 4.71 \\
BIM5 & + & $468 \pm 10.97^{* *}$ & 4.77 \\
BIM6 & + & $438 \pm 14.18^{*}$ & 4.56 \\
BIM7 & + & $466 \pm 12.66^{*}$ & 4.87 \\
BIM8 & + & $387 \pm 7.94$ & 4.71 \\
BIM9 & + & $414 \pm 6.51^{*}$ & 4.91 \\
BIM10 & + & $416 \pm 13.23^{*}$ & 4.85 \\
KLDS1.1028 & - & $356 \pm 11.79$ & 4.62 \\
KLDS1.1028 & + & $>12 \mathrm{~h}$ & - \\
BIM11 & + & $494 \pm 8.14^{* *}$ & 4.76 \\
BIM12 & + & $368 \pm 4.58$ & 4.67 \\
BIM13 & + & $389 \pm 9.17^{*}$ & 4.73 \\
BIM14 & + & $391 \pm 3.51^{*}$ & 4.72 \\
BIM15 & + & $491 \pm 10.41^{* *}$ & 4.78 \\
BIM16 & + & $406 \pm 4.16^{*}$ & 4.68 \\
BIM17 & + & $394 \pm 7.37^{*}$ & 4.64 \\
\hline
\end{tabular}

${ }^{1}+=$ strains cultured with phiLdb (multiplicity of infection $\left.=1\right) ;-=$ strains cultured without phiLdb.

*Significant difference $(P<0.05)$ compared with parent strains. **Significant difference $(P<0.01)$ compared with parent strains.

results in Table 5. The EOP1 of bacteriophage phiLdb propagated on $L$. bulgaricus strain KLDS1.1028 was at a low level originally. However, when bacteriophage phiLdb that used L. bulgaricus KLDS1.1028 as a host strain during stage 1 was used to infect $L$. bulgaricus strain KLDS1.1016, the EOP2 on L. bulgaricus strain KLDS1.1016 was 2 orders of magnitude higher than EOP1 $(P<0.01)$, which we inferred to be caused by a phage modification, such as methylation (Dupuis et al., 2013). Subsequently, when bacteriophage phiLdb that was propagated on L. bulgaricus strain KLDS1.1016 as a host strain during stage 2 was again propagated on $L$. bulgaricus KLDS1.1028, we found that EOP3 on L. bulgaricus KLDS1.1028 decreased sharply from EOP2 $(P$ $<0.01)$ and was very close to EOP1 $(P>0.05)$. This phenomenon implies that an R/M mechanism in L. bulgaricus KLDS1.1016 is induced by bacteriophage infection, but it did not appear in L. bulgaricus KLDS1.1028. All of the above results revealed that there is an R/M system in L. bulgaricus KLDS1.1016 that could exert an active resistance mechanism to bacteriophage phiLdb upon activation, and this mechanism was very likely to be implemented in the phage-resistant mutant BIM8. Meanwhile, in L. bulgaricus KLDS1.1028, the presence of an active R/M system cannot be ruled out, although future studies will be required to address this issue.

\section{Identification of the Genes Encoding R/M Systems in Bacteriophage-Resistant Mutants}

According to the high-level phage-resistant ability of bacteriophage-resistant mutants BIM8 and BIM12 and the inference of an active $\mathrm{R} / \mathrm{M}$ system in BIM8, the genes encoding the $\mathrm{R} / \mathrm{M}$ system were amplified using the primers listed in Table 2. No amplification products were detected for type II- and type III-encoding genes, but 3 subunits ( $H S D S, H S D R$, and $H S D M$ ) of a type I $\mathrm{R} / \mathrm{M}$ were all present (Figure 6); thus, only type I genes of $\mathrm{R} / \mathrm{M}$ systems exist in the 2 strains. The results showed that the lengths of the 3 amplified subunitencoding fragments were in the range of 500 to $650 \mathrm{bp}$, which were similar to the lengths of 3 published control sequences of $L$. delbrueckii strains in GenBank at the National Center for Biotechnology Information. Here, 3 reference cultures - L. delbrueckii ssp. bulgaricus ATCC 11842 (accession no. NC_008054.1), L. delbrueckii ssp. lactis NCC82 (accession no. AJ938156.1), and L. delbrueckii ssp. lactis NCC88 (accession no. AJ938155.1) were used for homologous alignments of HSDS, HSDR, and $H S D M$ genes.

Subsequently, we conducted a multiple-sequence similarity analysis (Table 6; Supplemental Figures S1, S2, and S3, https://doi.org/10.3168/jds.2017-13823). The HSDR and HSDM genes of BIM8 and BIM12 had a high sequence similarity of greater than $84.2 \%$ with the known genes, which illustrates that they share high homology, and are mostly orthologous to HSDR and $H S D M$ genes using the identification criteria described by Snel et al. (1999). Meanwhile, the HSDS gene showed a much lower sequence similarity of less than $40 \%$ compared with the reference cultures.

\section{DISCUSSION}

In this work, we aimed to isolate spontaneous bacteriophage-resistant mutants with good fermentation characteristics from Chinese traditional fermented dairy products and to identify their phage-resistance mechanism. For the typical bacteriophage phiLdb isolated from Chinese yogurt, we found that L. bulgaricus strains KLDS1.1016 and KLDS1.1028 were its host, and they were spontaneously isolated and 17 bacteriophage-resistant mutants were obtained. To exclude contaminants and ascertain the genomic variation, RAPD-PCR fingerprinting is a commonly used molecular technique for the preliminary characterization of the genetic diversity between a particular strain and its derivatives (Binetti et al., 2007b), including genotoxin-induced DNA damage and mutations (Atienzar et al., 2002). The RAPD-PCR technique 
has been applied to diversity identification in some $L$. delbrueckii species (Guglielmotti et al., 2006; Liu et al., 2012). The similarity coefficients between the parent strains and respective derivatives in this research were similar to those obtained by Capra et al. (2011), which indicates that the mutants in this research evolved directly from their respective parent strains rather than contaminants. Although no difference was shown in the amplification electrophoretogram between parent strains and the respective mutants, it is still possible that the phage resistance generated in the sensitive strains results from genomic changes because 4 primers are still insufficient to determine all genetic diversity besides base substitution. Thus, the similarity coef-
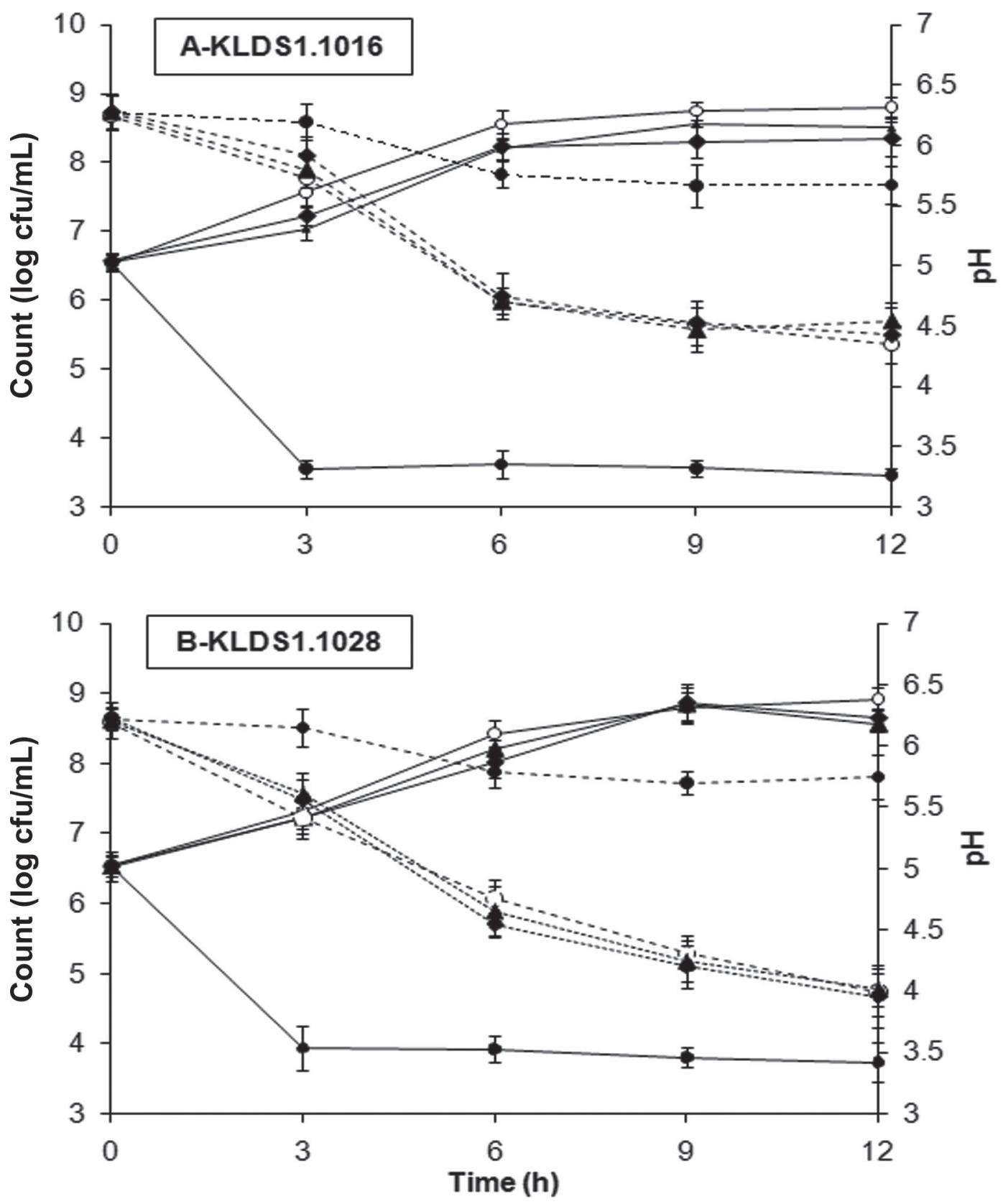

Figure 3. Growth (solid lines) and acidification (dotted lines) kinetics in Lactobacillus delbrueckii ssp. bulgaricus strains KLDS1.1016 and KLDS1.1028 and their respective bacteriophage-insensitive mutants (BIM) BIM8 and BIM12. Data markers denote parent strain cultivated without phiLdb $(\bigcirc)$, parent strain cultivated with phiLdb $(\bullet)$, phage-resistant mutant cultivated without phiLdb $(\bullet)$, and phage-resistant mutant cultivated with phiLdb $(\boldsymbol{\Lambda})$. Values are means \pm SD 
1910

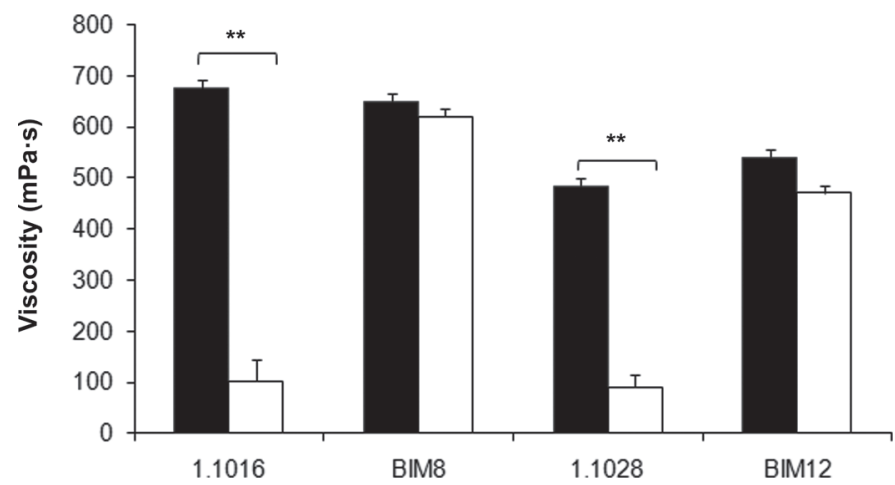

Figure 4. Curd viscosity of Lactobacillus delbrueckii ssp. bulgaricus strains KLDS1.1016 and KLDS1.1028 and their respective bacteriophage-insensitive mutants (BIM) BIM8 and BIM12. Mean \pm SD of 3 independent experiments. Black bars denote the culture without phiLdb (multiplicity of infection =1), and white bars denote the culture with phiLdb. Double asterisks indicate extremely significant difference $(P<0.01)$.

ficient differences between the resistant mutants and sensitive strains were probably caused by a mutation of the phage receptor or genes encoding the $\mathrm{R} / \mathrm{M}$ system.

Fermentation performance, especially milk-clotting ability and efficiency, plays a predominant role in the BIM application as starter cultures in yogurt or cheese production (Leroy and De Vuyst, 2004; Nakimbugwe et al., 2006), and this can be adversely affected by the presence of bacteriophages. Thus, based on the resistance stability of the resistant mutants in this study proven to be higher than that in Binetti et al. (2007a) for Streptococcus thermophilus and that in Capra et al. (2011) for Lactobacillus casei and Lactobacillus paracasei, the BIM could have great potential application value in yogurt production. After the test of curding, growth, and viscosity features in both parent strains and the respective bacteriophage-resistant mutants, BIM8 and BIM12 were respectively isolated from $L$. bulgaricus strains KLDS1.1016 and KLDS1.1028 and were proven to have good fermentation and milk coagulation attributes as potential dairy starter cultures. During cultivation of mutants BIM8 and BIM12, the main biological phenomenon was the extensive, sharp degradation of host cells due to phage lysis (González et al., 2010). Shortly afterward, the biomass of the hosts incubated with bacteriophage phiLdb achieved a low-level dynamic equilibrium until the decline phase of the bacteria, which has also been observed in a marine bacteria cycle (Isaacson et al., 2006). Meanwhile, an insufficient number of bacteria could impair lactic acid production, which would primarily prevent the $\mathrm{pH}$ from decreasing and affect the impartation of distinctive and fresh acidic flavors, milk coagulation and texturizing, and biochemical reactions (Carminati et al., 2010). However, the growth and $\mathrm{pH}$ of the BIM8 and BIM12 mutants showed very similar features regardless of whether they were cultured with bacteriophage phiLdb compared with their respective parent strains $(P>$ $0.05)$. This may be the reason why the proliferation and free acid generation of BIM8 and BIM12 were hardly affected by the phage, which is evidence of their high degree of bacteriophage phiLdb resistance.

Curd viscosity of fermented milk contributes to exopolysaccharide excretion by exopolysaccharide-positive strains (Weidenmaier and Peschel, 2008) and to casein coagulation because the $\mathrm{pH}$ declines to the isoelectric point of the protein (Osborn, 1963); thus, the viscosity change that was observed when the sensitive strains were incubated with phage occurred mainly because of the biomass reduction of the bacterial hosts. We also found that incubating the BIM8 and BIM12 mutants

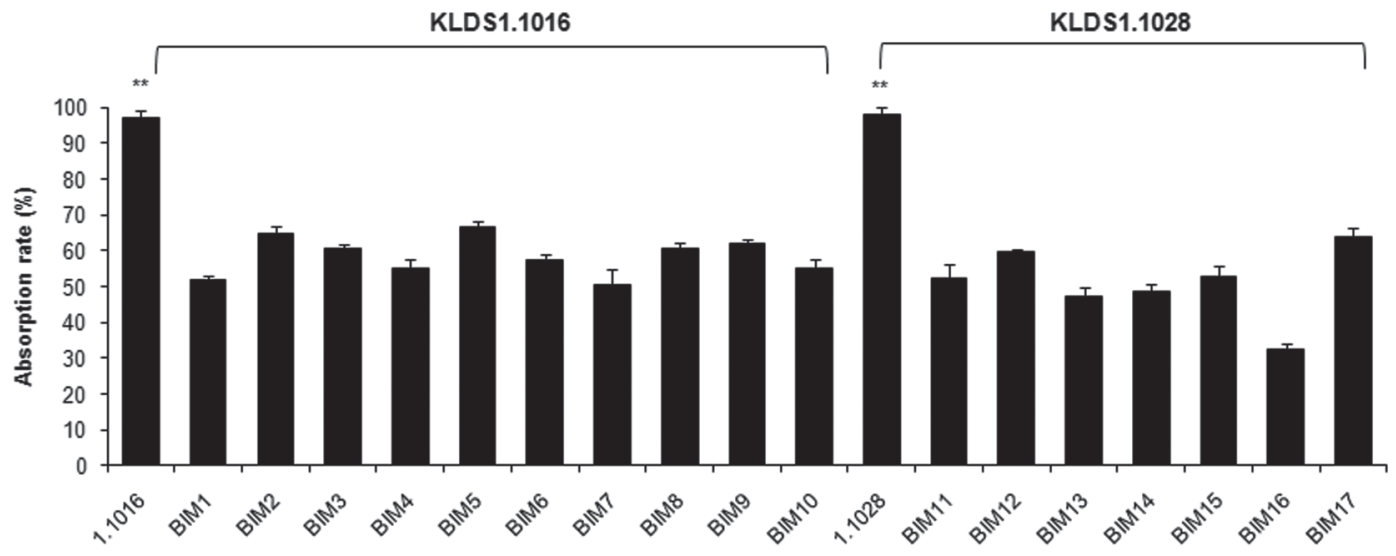

Figure 5. Adsorption rates of phiLdb on cells of Lactobacillus delbrueckii ssp. bulgaricus strains KLDS1.1016 and KLDS1.1028 and their respective bacteriophage-insensitive mutants (BIM) BIM1 to BIM17. Mean \pm standard deviation of 3 independent experiments. Double asterisks $\left({ }^{* *}\right)$ indicate extremely significant difference with other samples at the same time point $(P<0.01)$. 
Table 4. phiLdb adsorption rates (\%) of Lactobacillus delbrueckii ssp. bulgaricus strains KLDS1.1016 and KLDS1.1028 and their respective bacteriophage-insensitive mutants (BIM) BIM8 and BIM12 cell walls treated by proteinase K, lysozyme, SDS, and trichloroacetic acid (TCA) ${ }^{1}$

\begin{tabular}{lcccc}
\hline Treatment & KLDS1.1016 & BIM8 & KLDS1.1028 & BIM12 \\
\hline Control & $98.11 \pm 0.47^{\mathrm{a}}$ & $57.54 \pm 1.51^{\mathrm{a}}$ & $97.68 \pm 0.42^{\mathrm{a}}$ & $62.43 \pm 0.37^{\mathrm{a}}$ \\
Proteinase K & $97.47 \pm 0.29^{\mathrm{a}}$ & $54.65 \pm 2.24^{\mathrm{a}}$ & $97.10 \pm 1.78^{\mathrm{a}}$ & $56.81 \pm 1.86^{\mathrm{a}}$ \\
Lysozyme & $37.61 \pm 1.91^{\mathrm{b}}$ & $46.37 \pm 1.55^{\mathrm{b}}$ & $46.46 \pm 2.10^{\mathrm{b}}$ & $44.57 \pm 1.41^{\mathrm{b}}$ \\
SDS & $97.42 \pm 1.17^{\mathrm{a}}$ & $56.46 \pm 1.63^{\mathrm{a}}$ & $95.84 \pm 1.73^{\mathrm{a}}$ & $59.76 \pm 3.60^{\mathrm{a}}$ \\
TCA & $31.74 \pm 3.89^{\mathrm{b}}$ & $41.67 \pm 1.37^{\mathrm{b}}$ & $41.74 \pm 1.45^{\mathrm{b}}$ & $32.75 \pm 1.71^{\mathrm{b}}$ \\
\hline
\end{tabular}

${ }^{\mathrm{a}, \mathrm{b}}$ Different superscript letters indicate significant differences $(P<0.05)$.

${ }^{1}$ Duncan's multiple range tests were conducted. The cell walls without treatment were used for the control.

with phage usually resulted in slightly lower viscosity $(P<0.05)$ compared with that obtained when these strains were incubated without phage. This tendency is also displayed in other $L$. delbrueckii strains as a result of milk acidification kinetics (Guglielmotti et al., 2006). This signifies that the spontaneous phage-resistant mutants BIM8 and BIM12 can ferment milk in the presence of phages, which is a particularly beneficial attribute.

Currently, the demand for starter cultures in the food industry is focused on the following 2 points: to research and develop good commercial starter cultures from wild dairy products and to improve the environmental vigor of starter cultures by enhancing their bacteriophage resistance, which is still the most effective solution for avoiding industrial production failure on the basis of pure inoculation fermentation (Carminati et al., 2010). The above results suggest that the BIM8 and BIM12 mutants did not show any phenotypic changes compared with their original parent strains, and they exhibited outstanding fermentability and phage resistance, which are great attributes if they are to be used as commercial lactobacilli starter cultures.

In the phage-resistance mechanism analysis, the cellular attachment receptors of L. bulgaricus KLDS1.1016 and KLDS1.1028 for phage phiLdb probably were the teichoic acid on the cell wall. Teichoic acids and lipopolysaccharides are known to serve as phage adsorption sites in bacteria. In gram-positive bacteria, such as $L$. bulgaricus species, teichoic acids are the main compo- nents of the cell wall, whereas lipopolysaccharides exist only in gram-negative bacteria (Osborn, 1963; Weidenmaier and Peschel, 2008). In short, we speculate that changes of the teichoic acids, but not proteins, in the cell wall of the BIM8 and BIM12 mutants inhibited phiLdb absorption, which caused their phage resistance. Additionally, we found that the strain to strain adhesion, and even an intertwined net of bacteria, formed more easily in the phage-resistant mutant cultures, which ultimately proves that there were changes to the mutants' surfaces.

The bacteriophage resistance of the mutants BIM8 and BIM12 yielded an EOP $<1.8 \times 10^{-8}$, but their adsorption percentages were both greater than $50 \%$ (Figure 5). Thus, we speculate that these mutants have some other phage-resistance mechanism besides adsorption interference-for instance, superinfection exclusion, $\mathrm{R} / \mathrm{M}$ systems, abortive infection, or clustered regularly interspaced short palindromic repeats (CRISPR) systems (Sturino and Klaenhammer, 2006). Considering that BIM8 and BIM12 exhibited good growth characteristics during batches of 7 consecutive passages, the mechanism of abortive infection can be excluded as being responsible for the phage resistance in these mutants. Superinfection exclusion was also excluded because the bacteriophage phiLdb have been proven to be virulent phages (Wang et al., 2010). In addition, the CRISPR sequences of $L$. bulgaricus strains KLDS1.1016 and KLDS1.1028 and their phageresistant mutants (BIM8 and BIM12, respectively)

Table 5. Evidence of restriction-modification system mechanisms in Lactobacillus delbrueckii ssp. bulgaricus strain KLDS1.1016

\begin{tabular}{lllcc}
\hline & & \multicolumn{2}{c}{ EOP of } \\
\cline { 3 - 5 } Item & Phage & Host strain & KLDS 1.1028 & KLDS1.1016 \\
\hline EOP1 & phiLdb & KLDS1.1028 & $1.5 \times 10^{-3}$ & $7.8 \times 10^{-1}$ \\
EOP2 & phiLdb & KLDS 1.1016 & $-\overline{-}$ & - \\
EOP3 & phiLdb & KLDS 1.1028 & $6.5 \times 10^{-3}$ & \\
\hline
\end{tabular}

${ }^{1}$ Efficiency of plating (EOP) is expressed as the ratio of the host strains' titer to the reference strain's $(L$. bulgaricus ATCC11842) titer. - = not detected. 

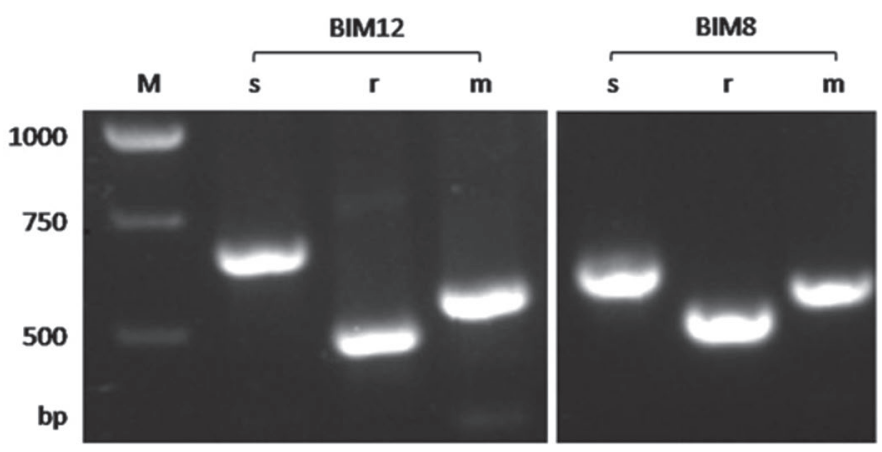

Figure 6. Gel electrophoretogram of a type I restriction-modification system encoding genes of bacteriophage-insensitive mutants (BIM) BIM8 and BIM12. $\mathrm{M}=$ marker; $\mathrm{s}=H S D S ; \mathrm{r}=H S D R ; \mathrm{m}=$ HSDM.

were amplified from their genomes, but we did not find any new direct repeat spacers inserted into the initial part of the first direct repeat (data not shown). This implies that the phage resistance did not result from a CRISPR system in these mutants.

It has been reported that if bacteriophage-resistant mutants exhibit a relatively high adsorption percentage to phage and a late lysis in broth, then the mutants are likely to possess an $\mathrm{R} / \mathrm{M}$ system with an active phage-resistance mechanism (Binetti et al., 2007b). In this study, although a relatively similar high level of adsorption $(>97 \%)$ to bacteriophage phiLdb particles was demonstrated in the 2 parent strains (Figure 5), the high lysis phenomenon was found to start from passage 2 in L. bulgaricus strain KLDS1.1016, which implies the possible existence of an R/M system in this strain; this theory has been proven in Lactobacillus helveticus (Clara et al., 1990). The R/M system is an important phage-resistance mechanism in bacteria. It

Table 6. Sequence similarity of 3 encoding genes of type I restrictionmodification system between bacteriophage-insensitive mutants (BIM) BIM8 and BIM12 and reference Lactobacillus delbrueckii strains on GenBank $^{1}$

\begin{tabular}{lccc}
\hline & \multicolumn{3}{c}{ Reference L. delbrueckii strain } \\
\cline { 2 - 4 } Strain and gene & ATCC11842 & NCC82 & NCC88 \\
\hline BIM8 & 31.6 & 37.3 & 38.7 \\
HSDS & 98.7 & 95.4 & 95.9 \\
HSDR & 85.5 & 97.7 & 98.1 \\
HSDM & & & \\
BIM12 & 31.5 & 38.4 & 39.3 \\
HSDS & 98.7 & 95.8 & 96.3 \\
HSDR & 84.5 & 97.4 & 96.4 \\
HSDM &
\end{tabular}

${ }^{1}$ Sequence similarity alignment was conducted using DNAman 6.0 (Lynnon Biosoft, San Ramon, CA) and expressed as the sequence identical percentage (\%) using the observed divergency method. was proven that mutants BIM8 and BIM12 have the type I R/M encoding genes HSDR, HSDM, and HSDS, but the sequence similarity of the $H S D S$ gene in both the mutants and reference strains was much lower than that of the HSDR and HSDM genes. It may be because the expressed proteins take on different functions in the $\mathrm{R} / \mathrm{M}$ mechanism. It has been reported that type I R/M systems are heteropentamers in which 1 HSDS subunit is responsible for the DNA specificity of the complex, 2 HSDM subunits are responsible for modification, and 2 HSDR subunits are responsible for endonuclease and helicase activities (O'Sullivan et al., 2000). This signifies that the tested mutants have a type I R/M complex with the same subunit constitution but totally different DNA sequences of the HSDS-encoding gene, as the specificities of the DNA structure and recognition domains are a crucial part of the type I R/M mechanism (O'Sullivan et al., 2000); this probably led to the inactive $\mathrm{R} / \mathrm{M}$ mechanism in $L$. bulgaricus strain KLDS1.1028 and its mutant BIM12. Additionally, considering that no plasmids were detected from L. bulgaricus strains KLDS1.1016 and KLDS1.1028 and their phage-resistant mutants, the type I R/M genes must be located in their chromosomes.

In conclusion, we identified 2 bacteriophage-resistant mutants, BIM8 and BIM12, of L. bulgaricus strains KLDS1.1016 and KLDS1.1028, and they showed fermentation performances as good as those of their parent strains, so mutants BIM8 and BIM12 have good potential as phage-resistant dairy starter cultures. The main bacteriophage-resistance mechanism of mutants BIM8 and BIM12 is adsorption interference and $\mathrm{R} / \mathrm{M}$ system. A CRISPR system was found in L. bulgaricus strains KLDS1.1016 and KLDS1.1028, but it did not affect the phage resistance of their mutants. Type I R/M systems were also found in BIM8 and BIM12, and the sequences of the $H S D R$ and $H S D M$ genes were highly homologous to previously published $L$. delbrueckii sequences. According to the lysis experiment, the type I $\mathrm{R} / \mathrm{M}$ system in mutant BIM8 was inferred to remain activatable upon exposure to bacteriophage phiLdb, whereas the sequence diversity of HSDS in BIM12 may result in its $\mathrm{R} / \mathrm{M}$ system deactivation. Pilot scale cofermentation tests with other commercial probiotics for preliminary industrial application and the interaction effect between adsorption interference and $\mathrm{R} / \mathrm{M}$ mechanism in mutants BIM8 and BIM12 could be possible fields of further research.

\section{ACKNOWLEDGMENTS}

This work was supported by International Technological Cooperation and Exchange Plan of Fujian 
Agriculture and Forestry University, China (grant no. KXGH17001), the National Natural Science Funds of China (grant no. 31171717), and the Scientific and Technological Innovation Team Support Plan of Fujian Agriculture and Forestry University (China, grant no. CXTD12009). We thank Jian Kong for the generous bacteriophage donation.

\section{REFERENCES}

Akopyanz, N., N. O. Bukanov, T. U. Westblom, S. Kresovich, and D. E. Berg. 1992. DNA diversity among clinical isolates of Helicobacter pylori detected by PCR-based RAPD fingerprinting. Nucleic Acids Res. 20:5137-5142.

Atienzar, F. A., P. Venier, A. N. Jha, and M. H. Depledge. 2002. Evaluation of the random amplified polymorphic DNA (RAPD) assay for the detection of DNA damage and mutations. Mut. Res. 521:151-163.

Binetti, A., N. Bailo, and J. Reinheimer. 2007a. Spontaneous phageresistant mutants of Streptococcus thermophilus: Isolation and technological characteristics. Int. Dairy J. 17:343-349.

Binetti, A., V. Suárez, P. Tailliez, and J. Reinheimer. 2007b. Characterization of spontaneous phage-resistant variants of Streptococcus thermophilus by randomly amplified polymorphic DNA analysis and identification of phage-resistance mechanisms. Int. Dairy J. $17: 1115-1122$.

Briggiler Marcó, M., M. F. Zacarías, G. Vinderola, J. A. Reinheimer, and A. Quiberoni. 2014. Biological and probiotic characterisation of spontaneous phage-resistant mutants of Lactobacillus plantarum. Int. Dairy J. 39:64-70.

Capra, M. L., D. Mercanti, L. Rossetti, J. Reinheimer, and A. Quiberoni. 2011. Isolation and phenotypic characterization of Lactobacillus casei and Lactobacillus paracasei bacteriophage-resistant mutants. J. Appl. Microbiol. 111:371-381.

Capra, M. L., M. M. Tibaldo, G. Vinderola, J. A. Reinheimer, and A. Quiberoni. 2014. Technological and probiotic characterisation of Lactobacillus casei/paracasei strains and their phage-resistant mutants. Int. Dairy J. 37:39-47.

Carminati, D., G. Giraffa, A. Quiberoni, A. Binetti, V. Suárez, and J. Reinheimer. 2010. Advances and trends in starter cultures for dairy fermentations. Pages 177-192 in Biotechnology of Lactic Acid Bacteria: Novel Applications. F. Mozzi, R. R. Raya, and G. M. Vignolo, ed. Wiley-Blackwell, Hoboken, NJ.

de los Reyes-Gavilán, C. G., G. K. Limsowtin, L. Séchaud, M. Veaux, and J.-P. Accolas. 1990. Evidence for a plasmid-linked restrictionmodification system in Lactobacillus helveticus. Appl. Environ. Microbiol. 56:3412-3419.

Dupuis, M.-E.., M. Villion, A. H. Magadán, and S. Moineau. 2013. CRISPR-Cas and restriction-modification systems are compatible and increase phage resistance. Nat. Commun. 4:2087.

Emond, E., and S. Moineau. 2007. Bacteriophages and food fermentations. Pages 93-124 in Bacteriophage: Genetics and Molecular Biology. S. McGrath and D. V. Sinderen, ed. Caister Academic Press, Cheshire, UK.

Forde, A., and G. F. Fitzgerald. 1999. Bacteriophage defence systems in lactic acid bacteria. Antonie van Leeuwenhoek 76:89-113.

Garcia-Doval, C., and M. J. van Raaij. 2013. Bacteriophage receptor recognition and nucleic acid transfer. Pages 489-518 in Structure and Physics of Viruses. Vol. 68. M. G. Mateu, ed. Springer, New York, NY.

Garneau, J. E., and S. Moineau. 2011. Bacteriophages of lactic acid bacteria and their impact on milk fermentations. Microb. Cell Fact. 10(Suppl. 1):S20.

González, A. R., P. García, and R. R. Raya. 2010. Bacteriophages of lactic acid bacteria. Pages 111-123 in Biotechnology of Lactic Acid Bacteria: Novel Applications. F. Mozzi, R. R. Raya, and G. M. Vignolo, ed. Wiley-Blackwell, Hoboken, NJ.
Gu, C. T., F. Wang, C. Y. Li, F. Liu, and G. C. Huo. 2012. Leuconostoc mesenteroides ssp. suionicum ssp. nov. Int. J. Syst. Evol. Microbiol. 62:1548-1551.

Guglielmotti, D. M., J. A. Reinheimer, A. G. Binetti, G. Giraffa, D. Carminati, and A. Quiberoni. 2006. Characterization of spontaneous phage-resistant derivatives of Lactobacillus delbrueckii commercial strains. Int. J. Food Microbiol. 111:126-133.

Hou, J.-C., F. Liu, D.-X. Ren, W.-W. Han, and Y.-O. Du. 2015. Effect of culturing conditions on the expression of key enzymes in the proteolytic system of Lactobacillus bulgaricus. J. Zhejiang Univ. Sci. B 16:317-326.

Isaacson, T., C. M. Damasceno, R. S. Saravanan, Y. He, C. Catalá, M. Saladié, and J. K. Rose. 2006. Sample extraction techniques for enhanced proteomic analysis of plant tissues. Nat. Protoc. 1:769-774.

Kutter, E. 2009. Phage host range and efficiency of plating. Methods Mol. Biol. 501:141-149.

Labrie, S. J., J. E. Samson, and S. Moineau. 2010. Bacteriophage resistance mechanisms. Nat. Rev. Microbiol. 8:317-327.

Leroy, F., and L. De Vuyst. 2004. Lactic acid bacteria as functional starter cultures for the food fermentation industry. Trends Food Sci. Technol. 15:67-78.

Li, B., D. Jin, S. Yu, S. Etareri Evivie, Z. Muhammad, G. Huo, and F. Liu. 2017. In vitro and in vivo evaluation of Lactobacillus delbrueckii ssp. bulgaricus KLDS1.0207 for the alleviative effect on lead toxicity. Nutrients 9:E845.

Liu, F., Y. Jiao, W. Guo, W. Yu, C. Gu, and X. Gao. 2012. Genetic stability of Lactobacillus delbrueckii ssp. bulgaricus mutant stain with low post-acidification. Zhongguo Rupin Gongye 40:11-14.

Liu, F., Y. H. Jiao, and G. C. Huo. 2013. Optimization of co-culture condition for Lactobacillus delbrueckii ssp. bulgaricus with weak post-acidification ability and Streptococcus thermophilus. Pages 1982-1986 in Proc. Advanced Materials Research. Trans Tech Publications, Zurich, Switzerland.

Marcó, M. B., D. Mercanti, J. A. Reinheimer, and A. Quiberoni. 2011. Performance of spontaneous phage-resistant derivatives of Lactobacillus plantarum in fermented milk manufacture. Int. Dairy J. 21:857-862.

Markwell, M. A. K., S. M. Haas, L. Bieber, and N. Tolbert. 1978. A modification of the Lowry procedure to simplify protein determination in membrane and lipoprotein samples. Anal. Biochem. $87: 206-210$

McGrath, S., G. F. Fitzgerald, and D. V. Sinderen. 2002. Identification and characterization of phage-resistance genes in temperate lactococcal bacteriophages. Mol. Microbiol. 43:509-520.

Moineau, S., and C. Lévesque. 2004. Control of bacteriophages in industrial fermentations. Pages 282-293 in Bacteriophages: Biology and Applications. E. Kutter and A. Sulakvelidze, ed. CRC Press, Boca Raton, FL.

Nakimbugwe, D., B. Masschalck, D. Deckers, L. Callewaert, A Aertsen, and C. W. Michiels. 2006. Cell wall substrate specificity of six different lysozymes and lysozyme inhibitory activity of bacterial extracts. FEMS Microbiol. Lett. 259:41-46.

O'Sullivan, D., D. P. Twomey, A. Coffey, C. Hill, G. F. Fitzgerald, and R. P. Ross. 2000. Novel type I restriction specificities through domain shuffling of HsdS subunits in Lactococcus lactis. Mol. Microbiol. 36:866-875.

Osborn, M. J. 1963. Studies on the gram-negative cell wall, I. Evidence for the role of 2-keto-3-deoxyoctonate in the lipopolysaccharide of Salmonella typhimurium. Proc. Natl. Acad. Sci. U.S.A. 50:499-506.

Parente, P., and T. M. Cogan. 2004. Starter cultures: General aspects. Pages 123-133 in Cheese: Chemistry, Physics and Microbiology: General Aspects. Vol. 1. P. F. Fox, P. L. McSweeney, T. M. Cogan, and T. P. Guinee, ed. Elsevier Academic Press, Amsterdam, the Netherlands.

Parvez, S., K. A. Malik, S. Ah Kang, and H. Y. Kim. 2006. Probiotics and their fermented food products are beneficial for health. J. Appl. Microbiol. 100:1171-1185.

Pillidge, C. J., L. J. Collins, L. J. Ward, B. M. Cantillon, B. D. Shaw, M. J. Timmins, H. A. Heap, and K. M. Polzin. 2000. Efficacy of four conjugal lactococcal phage resistance plasmids against 
phage in commercial Lactococcus lactis ssp. cremoris cheese starter strains. Int. Dairy J. 10:617-625.

Quiberoni, A., D. M. Guglielmotti, and J. A. Reinheimer. 2003. Inactivation of Lactobacillus delbrueckii bacteriophages by heat and biocides. Int. J. Food Microbiol. 84:51-62.

Quiberoni, A., J. I. Stiefel, and J. A. Reinheimer. 2000. Characterization of phage receptors in Streptococcus thermophilus using purified cell walls obtained by a simple protocol. J. Appl. Microbiol. 89:1059-1065.

Snel, B., P. Bork, and M. A. Huynen. 1999. Genome phylogeny based on gene content. Nat. Genet. 21:108-110.

Sturino, J. M., and T. R. Klaenhammer. 2006. Engineered bacteriophage-defence systems in bioprocessing. Nat. Rev. Microbiol. 4:395-404.

Torriani, S., G. Zapparoli, and F. Dellaglio. 1999. Use of PCR-based methods for rapid differentiation of Lactobacillus delbrueckii ssp. bulgaricus and L. delbrueckii ssp. lactis. Appl. Environ. Microbiol. 65:4351-4356.

Valyasevi, R., W. Sandine, and B. Geller. 1990. The bacteriophage kh receptor of Lactococcus lactis ssp. cremoris $\mathrm{KH}$ is the rhamnose of the extracellular wall polysaccharide. Appl. Environ. Microbiol $56: 1882-1889$

Vauterin, L., and P. Vauterin. 1992. Computer-aided objective comparison of electrophoresis patterns for grouping and identification of microorganisms. Eur. Microbiol. 1:37-41.

Wang, S., J. Kong, C. Gao, T. Guo, and X. Liu. 2010. Isolation and characterization of a novel virulent phage (phiLdb) of Lactobacillus delbrueckii. Int. J. Food Microbiol. 137:22-27.

Weidenmaier, C., and A. Peschel. 2008. Teichoic acids and related cellwall glycopolymers in Gram-positive physiology and host interactions. Nat. Rev. Microbiol. 6:276-287.

Wilson, K. 1987. Preparation of genomic DNA from bacteria. Sections 2.4.1-2.4.5 in Current Protocols in Molecular Biology. F. M. Ausubel, R. Brent, R. E. Kingston, D. D. Moore, J. G. Seidman, J. A. Smith, and K. Struhl, ed. Wiley, New York, NY.

Zago, M., L. Orrù, L. Rossetti, A. Lamontanara, M. E. Fornasari, B. Bonvini, A. Meucci, D. Carminati, L. Cattivelli, and G. Giraffa. 2017. Survey on the phage resistance mechanisms displayed by a dairy Lactobacillus helveticus strain. Food Microbiol. 66:110-116. 